\title{
Association of Osteopontin Gene Promoter Single Nucleotide Polymorphisms with Bull Semen Quality
}

\author{
Rick W. Rorie*, Chance L. Williams, Toby D. Lester \\ Department of Animal Science, University of Arkansas, Fayetteville, AR, USA \\ Email: "rrorie@uark.edu
}

Received 22 December 2015; accepted 14 February 2016; published 17 February 2016

Copyright (C) 2016 by authors and Scientific Research Publishing Inc.

This work is licensed under the Creative Commons Attribution International License (CC BY). http://creativecommons.org/licenses/by/4.0/

(c) (i) Open Access

\begin{abstract}
Osteopontin (OPN) is a protein found at higher concentrations in the seminal plasma of bulls with above average fertility. Polymorphisms have been reported within the OPN gene promoter that can affect production of this protein and thus, affect fertility. Therefore, Angus $(n=5)$ and Angus $x$ Gelbvieh (Balancer, $n=14$ ) and Angus $x$ Brahman $(n=15)$ bulls were evaluated for presence of single nucleotide polymorphisms (SNP) in the Bos taurus OPN gene (GenBank: AY878328.1) promoter region, and their possible effects on bull semen quality as evaluated by computer-assisted semen analysis (CASA). Semen was collected by electroejaculation 6 to 9 times from each bull, and each semen collection was evaluated by CASA for motile, progressive and rapid sperm within 5 mins of ejaculation. The bulls were genotyped for reported single nucleotide polymorphisms (SNP) in the promoter region of the OPN gene through amplification of two 700 base pair (bp) DNA fragments and sequencing of the resulting PCR products. Seven SNP sites were identified, at bp $3379,3490,3492,5075,5205,5209$, and 5263 of the OPN gene. The SNP identified at bp 5205, 5209 and 5263 had not been previously reported. Individual SNP sites were evaluated as the main effect on CASA sperm motility variables in a SAS MIXED model for repeated measures. A thymine to guanine substitution at bp 3379 was associated with increased $(P \leq 0.02)$ percentage of motile, progressive and rapid sperm in Angus $x$ Brahman bulls, and tended $(P \leq 0.10)$ to increase the same sperm motility parameters in Angus, and Angus $x$ Gelbvieh bulls. The percentages of motile, progressive and rapid sperm were similar $(P \geq 0.05)$ among genotypes for the other 6 SNP identified. These results suggest that identification and genotyping of polymorphisms within the promoter region of the bovine OPN gene may be useful for selecting bulls with improved sperm motility parameters.
\end{abstract}

\footnotetext{
"Corresponding author.
} 


\section{Keywords}

\section{Osteopontin, Polymorphism, Sperm Motility, Bull}

\section{Introduction}

Osteopontin (OPN) is a ubiquitous, multi-function protein that has been found in higher concentrations in ejaculates of bulls that produce higher conception rates [1]. Cancel et al. [2] find that in the bull, OPN is secreted in the ampullae and seminal vesicles, where it is believed to bind to sperm through CD44 and surface integrins. Osteopontin has also been shown to facilitate capacitation and viability of bovine sperm [3]. Ejaculated sperm carries the bound OPN protein to the site of fertilization [4] where it is thought to play a role in the sperm-egg interaction through OPN-integrin complexes present on the surface of the sperm and oocyte [5].

In vitro studies indicate that pre-treatment of either bovine semen or oocytes with purified OPN increases fertilization rate and embryo development [6]. Ejaculated bovine sperm treated with OPN antibodies prior to in vitro fertilization results in decreased fertilization rates and increased polyspermy [7]. These findings are in agreement with Hao et al. [8], who report OPN reduced polyspermy in a dose dependent manner, while increasing fertilization efficiency during pig in vitro fertilization.

Osteopontin is present in bovine milk at a concentration of about $18 \mathrm{mg} / \mathrm{L}$ [9]. While $18 \mathrm{mg} / \mathrm{L}$ only represents about $0.05 \%$ of the total milk protein, studies have demonstrated that polymorphisms within the OPN gene promoter region show significant associations with milk protein concentrations [10] [11]. Because higher concentrations of OPN in semen are associated with fertility, any polymorphism that occurs in the OPN gene may affect concentration of OPN in seminal plasma and thus, serve as a marker for fertility. This study investigates the polymorphic nature of the bovine OPN gene promoter region to determine any association of polymorphisms with bull semen quality.

\section{Materials and Methods}

\subsection{Bull Management}

The University of Arkansas Animal Care and Use Committee approved all practices and techniques utilized in this study. A group of Angus ( $n=5)$ and Angus x Gelbvieh (Balancer, $n=14$ ) bulls ranging in age from 5 to $9 \mathrm{y}$ and weighing between 710 to $955 \mathrm{~kg}$ were maintained at the University of Arkansas Beef Research Unit. These bulls were allotted to two separate drylots to reduce social (dominance) stress. The bulls were fed $0.45 \mathrm{~kg}$ of high concentrate feed 3 times a wk and ad libitum grass hay. The concentrate feed was formulated by University of Arkansas feed mill to contain 10\% crude protein, and the grass hay was produced at the University of Arkansas Beef Research Unit and contained 89\% dry matter and 11.6\% crude protein. A second group of bulls (Angus $\mathrm{x}$ Brahman, $\mathrm{n}=15$ ) bulls were maintained at the USDA Small Farms Research Center near Booneville, Arkansas. These bulls, averaging 16 mo of age and $478 \mathrm{~kg}$ body weight, were maintained on common bermudagrass pastures overseeded with rye grass.

Before inclusion in the study, all bulls received a breeding soundness evaluation to insure they met or exceeded the minimum acceptable standards for semen quality. Semen was collected by electroejaculation weekly from the Angus and Angus x Gelbvieh bulls over a 9 wk period during summer (July 15 through September 19). The Angus x Brahman bulls were collected monthly from May to September. Immediately after collection, semen samples were placed into a water bath at $35^{\circ} \mathrm{C}$ to avoid temperature shock.

\subsection{Semen Analysis}

Each semen collection was analyzed using a computer assisted sperm analysis (CASA; Hamilton Thorne Biosciences, Beverly, MA) within 5 mins of ejaculation. Prior to analysis, each semen sample was diluted with Dulbecco's PBS (\#D-5773, Sigma, St. Louis, MO) to achieve a concentration of $\sim 25 \times 106 \mathrm{sperm} / \mathrm{mL}$ before loading onto a 2X-CEL (Hamilton Thorne Biosciences) slide. The CASA system scanned 10 areas along the length of the slide and captured 30 video frames per viewing area to construct a composite of the sperm motility variables. A minimum of 400 spermatozoa was counted on each slide to achieve a representation of the entire se- 
men collection sample. The sperm variables measured were percent motile, progressive and rapid sperm. Motile sperm were defined as those with a path velocity $\geq 30 \mu \mathrm{m} / \mathrm{s}$ and progressive velocity $\geq 15 \mu \mathrm{m} / \mathrm{s}$. Progressive sperm had a path velocity $\geq 50 \mu \mathrm{m} / \mathrm{s}$ and straightness $\geq 70 \%$. Rapid sperm were defined as the percentage of progressive sperm with path velocity $>50 \mu \mathrm{m} / \mathrm{s}$.

\subsection{DNA Extraction}

Blood samples were obtained from each test bull via tail vein in $8 \mathrm{~mL}$ vacuum tubes containing EDTA (Vacutainer \#366643, BD, Franklin Lakes, NJ), and were placed on ice for transport to the lab. Genomic DNA was extracted using a DNeasy Blood and Tissue Kit (QIAGEN, Cat. No. 69504; Valencia, CA) using a mammalian whole blood protocol. Isolated DNA was rehydrated in TRIS-EDTA (TE) buffer (10 mM TRIS, 1 mM EDTA, pH 8.0, Sigma \#93283) and quantified using a Qubit fluorometer (Invitrogen, Cat. No. Q32857; Eugene, OR), utilizing a Quant-iT dsDNA high sensitivity assay kit (Invitrogen; Cat. No. Q32854). Following DNA quantitation, samples were frozen and stored at $-20^{\circ} \mathrm{C}$ until use. Upon thawing, DNA samples were diluted to a concentration of $20 \mathrm{ng} / \mu \mathrm{L}$ in sterile, PCR-quality water and stored at $4^{\circ} \mathrm{C}$.

\subsection{Primer Design}

Primers for PCR amplification were designed using Primer 3 (v1.1.4) software [12]. The desired area of amplification was copied from the reference sequence of the OPN gene [GenBank: AY878328.1] and inserted into Primer 3 to generate forward and reverse primers flanking the desired area of amplification. The selected primers were then checked for uniqueness within the Bos taurus genome using Basic Local Alignment Search Tool (BLAST; National Center for Biotechnology Information, Bethesda, MD).

Two separate sets of primers were used to produce two DNA fragments of interest. Primers OPN3307F: 5'AGC CCA CCA CCA AAT ACC TA-3' and OPN4006R: 5'-TCT GAA GGA CTG GCT TAG ATT TC-3' were used to amplify a 700 base pair (bp) region between bp 3307 and 4006 of the OPN gene promoter region that had reported polymorphisms [11], including OPN3907 which is believed to be a polymorphism linked to protein concentration in milk. Another set of primers, OPN4816F: 5'-TCC CTC CCT CTA CGT TTT CA-3' and OPN5528R: 5'-CAT CCC AAA AGG GCA TAG AA-3', amplified the region between bp 4816 and 5528 of the OPN gene promoter region that also had reported polymorphisms [11].

\subsection{PCR Conditions and Sequencing}

Polymerase chain reaction amplification was performed in a $50 \mu \mathrm{L}$ total reaction volume that included $5 \mu \mathrm{L}$ of $10 \mathrm{x}$ PCR buffer, $1.5 \mathrm{mM} \mathrm{MgCl}, 250 \mu \mathrm{M}$ dNTP mix, $40 \mathrm{pM}$ of each primer, $100 \mathrm{ng}$ of genomic DNA and 2 units of Biolase DNA polymerase (Bioline USA, Inc; Taunton, MA). Annealing temperature gradients were run to test the uniqueness of the primers and confirm the annealing temperature. The temperature cycles for DNA amplification were as follows: 35 cycles of $94^{\circ} \mathrm{C}$ denaturation for $1 \mathrm{~m}, 59^{\circ} \mathrm{C}$ annealing temperature for $45 \mathrm{~s}$ and $72^{\circ} \mathrm{C}$ for $1 \mathrm{~m}$ extension time. Before sequencing, the PCR product was purified using a QIAquick PCR purification kit (QIAGEN; Cat. No. 28104). A sample of each purified product was run through a $1 \%$ agarose gel using TBE buffer (\#BM-260A, Boston BioProducts, Ashland, MA) to confirm size and the presence of a single PCR product.

An ABI 3130xe (AME Bioscience; Toroed, Norway) analyzer was used for automated DNA sequencing by the DNA Technologies Laboratory at the University of Arkansas. Electropherograms for both forward and reverse complement DNA sequences were evaluated for polymorphisms using BioEdit Sequence Alignment Editor (Ibis Therapeutics, Version 7.0.5.3). Completed DNA sequences were aligned in ClustalW2 (European Molecular Biology Laboratory Outstation-European Bioinformatics Institute, Cambridge, UK; Version 2.0) to identify differences in genetic sequences among bulls and the reported normal reference sequence.

\subsection{Statistical Analysis}

Data were analyzed using the PROC MIXED model of SAS (SAS Inst., Inc.; Cary, NC) to determine any effect of individual SNP genotypes on CASA sperm motility measures. The percentages of motile, progressive and rapid sperm were described using the MEANS procedure. Differences at $P<0.05$ were considered to be statistically significant. Within bulls, sperm motility data from each semen collection were analyzed as repeated 
measures over time. Because of the differences in location, management, and semen collection interval, data collected from Angus and Angus $\times$ Gelbvieh bulls were analyzed separately from data collected from the Angus $\mathrm{x}$ Brahman bulls.

\section{Results}

Through amplification and sequencing of two separate DNA fragments, (bp 3307 to 4006 and bp 4816 to 5528; 700 and 707 bp products, respectively) of the OPN promoter region, 7 SNP sites were identified. Reported SNP sites were confirmed at bp 3379, 3490, 3492, and 5075, while previously unreported SNP were found at bp 5205, 5209, and 5263 of the OPN gene. Genotype and allele frequencies are summarized in Table 1. Minor allele frequencies for each sire group are presented in Table 2.

The minor allele frequencies reported in Holstein bulls for SNP 3379, 3490 and 3492 are 0.61, 0.80 and 0.61, respectively [11]. Across all beef bulls evaluated, the minor allele frequencies for the same SNP were lower at $0.45,0.16$ and 0.43 , respectively. The minor allele frequency for the 7 SNP varied across sire groups (Table 2). The SNP located at bp3490, 5075, 5209 and 5263 of the OPN gene promoter occurred the least frequently in the Brahman $x$ Angus bulls evaluated.

Genotypes within each SNP were compared for any effect on the percentage of motile, progressive and rapid sperm, as determined by CASA. No differences $(P>0.05)$ were detected in the percentages of motile, progressive and rapid sperm for bulls represented in genotypes for SNP 3490, 3492, 5075, 5205, 5209 and 5263. Substitution of guanine for thymine at bp 3379 was associated with an increase $(P \leq 0.02)$ in the percentage of motile, progressive and rapid sperm collected from Brahman x Angus bulls (Table 3). This substitution also resulted in a trend $(P \leq 0.10)$ for increased motile, progressive and rapid sperm in Angus and Angus x Gelbvieh bulls.

Table 1. Genotype and allele frequencies of single nucleotide polymorphisms within the promoter region of the OPN gene.

\begin{tabular}{cccccc}
\hline Polymorphism $^{\mathrm{a}}$ & Homozygous primary allele & Heterozygous & Homozygous minor allele & PAF $^{\mathrm{b}}$ & MAF $^{\mathrm{c}}$ \\
\hline T3379G & 0.294 & 0.500 & 0.206 & 0.544 & 0.456 \\
G3490A & 0.735 & 0.206 & 0.059 & 0.838 & 0.162 \\
A3492G & 0.265 & 0.617 & 0.118 & 0.574 & 0.426 \\
C5075T & 0.676 & 0.265 & 0.059 & 0.809 & 0.191 \\
C5205T & 0.765 & 0.206 & 0.029 & 0.868 & 0.132 \\
G5209A & 0.618 & 0.353 & 0.029 & 0.794 & 0.206 \\
G5263A & 0.882 & 0.118 & ---- & 0.941 & 0.059 \\
\hline
\end{tabular}

${ }^{\text {a }}$ Single nucleotide polymorphism occurred at the base pair number indicated; the first letter represents the primary allele reported for the normal reference sequence and the letter following the number represents the resulting minor allele; ${ }^{b}$ Primary Allele Frequency; ${ }^{\mathrm{C}}$ Minor Allele Frequency.

Table 2. Minor allele frequency of single nucleotide polymorphisms within the promoter region of the OPN gene for different sire groups.

\begin{tabular}{cccc}
\hline & Angus $(\mathrm{n}=5)$ & Angus x Gelbvieh $(\mathrm{n}=14)^{\text {Brahman }^{\mathrm{A}} \text { Angus }(\mathrm{n}=15)}$ \\
\hline Polymorphism $^{\mathrm{a}}$ & Frequency $^{\mathrm{b}}$ & Frequency $^{\mathrm{b}}$ & Frequency $^{\mathrm{b}}$ \\
\hline T3379G & 0.40 & 0.43 & 0.50 \\
G3490A & 0.20 & 0.32 & 0.00 \\
A3492G & 0.50 & 0.39 & 0.43 \\
C5075T & 0.20 & 0.32 & 0.13 \\
C5205T & 0.10 & 0.14 & 0.13 \\
G5209A & 0.20 & 0.29 & 0.13 \\
G5263A & 0.10 & 0.14 & 0.03 \\
\hline
\end{tabular}

${ }^{\mathrm{a}}$ The first letter represents the primary allele found in the reported, normal reference sequence and the letter following the base pair number represents the resulting minor allele. ${ }^{\mathrm{b}}$ Minor allele frequency. 
Table 3. Effects of osteopontin polymorphism T3379G on mean percentage $( \pm$ SE) of motile, rapid progressive and rapid sperm of Angus x Gelbvieh and Angus x Brahman bulls.

\begin{tabular}{|c|c|c|c|c|}
\hline \multirow[b]{2}{*}{ Sperm motility parameter ${ }^{c}$} & \multicolumn{3}{|c|}{ T3379G Genotypes } & \multirow{2}{*}{$P$ value } \\
\hline & TT & TG & GG & \\
\hline \multicolumn{5}{|l|}{ Motile sperm (\%) } \\
\hline Angus and Angus-Gelbvieh & $58.4 \pm 3.2^{\mathrm{a}}$ & $60.4 \pm 3.0^{\mathrm{a}}$ & $67.6 \pm 4.1^{\mathrm{a}}$ & 0.096 \\
\hline Angus-Brahman & $47.4 \pm 5.8^{\mathrm{b}}$ & $54.7 \pm 3.2^{\mathrm{b}}$ & $72.7 \pm 5.8^{\mathrm{a}}$ & 0.017 \\
\hline \multicolumn{5}{|l|}{ Progressive sperm (\%) } \\
\hline Angus and Angus-Gelbvieh & $39.8 \pm 2.5^{\mathrm{a}}$ & $44.1 \pm 2.3^{\mathrm{a}}$ & $46.8 \pm 3.2^{\mathrm{a}}$ & 0.104 \\
\hline Angus-Brahman & $36.9 \pm 5.2^{\mathrm{b}}$ & $42.2 \pm 2.9^{\mathrm{b}}$ & $57.7 \pm 5.2^{\mathrm{a}}$ & 0.023 \\
\hline \multicolumn{5}{|l|}{ Rapid sperm (\%) } \\
\hline Angus and Angus-Gelbvieh & $54.4 \pm 3.3^{\mathrm{a}}$ & $57.8 \pm 3.0^{\mathrm{a}}$ & $64.3 \pm 4.1^{\mathrm{a}}$ & 0.080 \\
\hline Angus-Brahman & $42.8 \pm 5.7^{\mathrm{b}}$ & $48.3 \pm 3.1^{\mathrm{b}}$ & $66.2 \pm 5.7^{\mathrm{a}}$ & 0.016 \\
\hline
\end{tabular}

${ }^{\mathrm{a}, \mathrm{b}}$ Means within rows with different superscripts are significantly different $(P<0.05)$. ${ }^{\mathrm{c}}$ Motile $=$ path velocity $\geq 30 \mu \mathrm{m} / \mathrm{s}$ and progressive velocity $\geq 15$ $\mu \mathrm{m} / \mathrm{s} ;$ Progressive $=$ path velocity $\geq 50 \mu \mathrm{m} / \mathrm{s}$ and straightness $\geq 70 \%$; Rapid $=$ progressive $\%$ with path velocity $>50 \mu \mathrm{m} / \mathrm{s}$.

Numerically, the percentages of motile, progressive and rapid sperm showed consecutive increases for semen collected from bulls with the TT, TG and GG genotypes, respectively.

Genotypes within each SNP were compared for any effect on the percentage of motile, progressive and rapid sperm, as determined by CASA. No differences $(P>0.05)$ were detected in the percentages of motile, progressive and rapid sperm for bulls represented in genotypes for SNP 3490, 3492, 5075, 5205, 5209 and 5263. Substitution of guanine for thymine at bp 3379 was associated with an increase $(P \leq 0.02)$ in the percentage of motile, progressive and rapid sperm collected from Brahman x Angus bulls (Table 3). This substitution also resulted in a trend $(P \leq 0.10)$ for increased motile, progressive and rapid sperm in Angus and Angus x Gelbvieh bulls. Numerically, the percentages of motile, progressive and rapid sperm showed consecutive increases for semen collected from bulls with the TT, TG and GG genotypes, respectively.

\section{Discussion}

Killian et al. [1] evaluated proteins in the seminal plasma of Holstein bulls for potential markers for fertility. The bulls were of known fertility, based on pregnancy date from least 1000 inseminations per bull. A $55 \mathrm{kDa}$ protein was found in higher concentrations in the seminal plasma of high fertility bulls when compared with bulls of average or below average fertility. This $55 \mathrm{kDa}$ protein was later identified as osteopontin [13]. Any SNP within the osteopontin gene could positively or negatively influence expression of this protein in seminal plasma and thus, influence fertility. Therefore, the current study was conducted to identify any such polymorphisms that might influence on bull fertility.

Our results confirmed previously reported SNP sites at bp 3379, 3490, 3492, and 5075, and identified previously unreported SNP at bp 5205, 5209, and 5263 of the OPN gene. A previous study [11] reported a SNP located at bp 3907 influenced milk qualitative traits including protein content. This SNP resulted in deletion of a thymine within a polyT tract. The frequency of this polymorphism was reported to be only 0.05 ; none of the bulls in the current study were found to have this SNP.

Bull fertility assessment was based on in vitro sperm motility variables measured by CASA in the current study. This type of analysis provides objective, repeatable assessment of sperm characteristics [14], which correlate well with fertility in bulls [15] [16]. Farrell et al. [15] evaluated the relationship various CASA sperm variables and lifetime fertility of Holstein bulls, based on non-return rates after insemination. Sperm motility was identified as the single most important sperm parameter associated with fertility. Lin et al. [17] investigated potential candidate genes for sperm quality and fertility in boars and found that a polymorphism in intron 6 of the porcine OPN gene was associated with sperm motility and litter size. In the present study, a SNP at bp 3379 of the OPN promoter region was associated with an increase in the percentage of motile, progressive and rapid 
sperm. The minor allele frequency of this polymorphism ranged from 0.40 to 0.50 among the groups of bulls evaluated. The frequency that the minor allele was detected suggests it occurs relatively frequently and could be used as a basis for selection.

\section{Conclusion}

Seven polymorphisms were identified within the promoter region of the bovine osteopontin gene. A SNP at bp 3379, resulting in substitution of guanine for thymine, was associated with improved sperm motility, progressive motility and progressive sperm with rapid motility. Although our data was limited, the results of this study suggested that further study was merited to determine associations OPN promoter and gene polymorphisms with bull semen quality.

\section{Acknowledgements}

The authors acknowledge the University of Arkansas Agricultural Experiment Station and the Department of Animal Science for their financial support.

\section{References}

[1] Killian, G.J., Chapman, D.A. and Rogowski, L.A. (1993) Fertility-Associated Proteins in Holstein Bull Seminal Plasma. Biology of Reproduction, 49, 1202-1207. http://dx.doi.org/10.1095/biolreprod49.6.1202

[2] Cancel, A.M., Chapman, D.A. and Killian, G.J. (1999) Osteopontin Localization in the Holstein Bull Reproductive Tract. Biology of Reproduction, 60, 454-460. http://dx.doi.org/10.1095/biolreprod60.2.454

[3] Erikson, D.W., Way, A.L., Bertolla, R.P., Chapman, D.A. and Killian, G.J. (2007) Influence of Osteopontin, Casein and Oviductal Fluid on Bovine Sperm Capacitation. Animal Reproduction, 4, 103-112.

[4] Souza, C.E.A., Moura, A.A., Monaco, E. and Killian, G.J. (2008) Binding Patterns of Bovine Seminal Plasma Proteins A1/A2, 30kDa and Osteopontin on Ejaculated Sperm before and after Incubation with Isthmic Ampullary Oviductal Fluid. Animal Reproduction Science, 105, 72-89. http://dx.doi.org/10.1016/j.anireprosci.2007.11.027

[5] Gabler, C., Chapman, D.A. and Killian, G.J. (2003) Expression and Presence of Osteopontin and Integrins in the Bovine Oviduct during the Estrous Cycle. Reproduction, 126, 721-729. http://dx.doi.org/10.1530/rep.0.1260721

[6] Goncalves, R.F., Chapman, D.A., Bertolla, R.P., Eder, I. and Killian, G.J. (2008) Pre-Treatment of Cattle Semen or Oocytes with Purified Milk Osteopontin Affects in Vitro Fertilization and Embryo Development. Animal Reproduction Science, 108, 375-383. http://dx.doi.org/10.1016/j.anireprosci.2007.09.006

[7] Erikson, D.W., Way, A.L., Chapman, D.A. and Killian, G.J. (2007) Detection of Osteopontin on Holstein Bull Spermatozoa, in Cauda Epididymal Fluid and Testis Homogenates, and Its Potential Role in Bovine Fertilization. Reproduction, 133, 909-917. http://dx.doi.org/10.1530/REP-06-0228

[8] Hao, Y., Mathialagan, N., Walters, E., Mao, J., Lai, L., Becker, D., Crister, L.W. and Prather, R.S. (2006) Osteopontin Reduces Polyspermy during in Vitro Fertilization of Porcine Oocytes. Biology of Reproduction, 75, 726-733. http://dx.doi.org/10.1095/biolreprod.106.052589

[9] Schack, L., Lange, A., Kelsen, J., Agnholt, J., Christensen, B., Petersen, T.E. and Sorensen, E.S. (2009) Considerable Variation in the Concentration of Osteopontin in Human Milk, Bovine Milk, and Infant Formulas. Journal of Dairy Science, 92, 5378-5385. http://dx.doi.org/10.3168/jds.2009-2360

[10] Leonard, S., Khatib, H., Schutzkus, V., Chang, Y.M. and Maltecca, C. (2005) Effects of the Osteopontin Gene Variants on Milk Production Traits in Dairy Cattle. Journal of Dairy Science, 88, 4083-4086. http://dx.doi.org/10.3168/jds.S0022-0302(05)73092-7

[11] Schnabel, R.D., Kim, J.J., Ashwell, M.S., Sonstegard, T.S., Van Tassell, C.P., Connor, E.E. and Taylor, J.F. (2005) Fine-Mapping Milk Production Quantitative Trait Loci on BTA6: Analysis of the Bovine Osteopontin Gene. Proceedings of the National Academy of Sciences of the United States of America, 102, 6896-6901. http://dx.doi.org/10.1073/pnas.0502398102

[12] Rozen, S. and Skaletsky, H.J. (2000) Primer 3 on the WWW for General Users and for Biologist Programmers. In: Krawetz, S. and Misener, S., Eds., Bioinformatics Methods and Protocols: Methods in Molecular Biology, Humana Press, Totowa, 365-386.

[13] Cancel, A.M., Chapman, D.A. and Killian, G.J. (1997) Osteopontin Is the 55 kDa Fertility-Associated Protein in Holstein Bull Seminal Plasma. Biology of Reproduction, 57, 1293-1301. http://dx.doi.org/10.1095/biolreprod57.6.1293

[14] Verstegen, J., Iguer-Ouada, M. and Onclin, K. (2002) Computer Assisted Semen Analyzers in Andrology Research and 
Veterinary Practice. Theriogenology, 57, 149-179. http://dx.doi.org/10.1016/S0093-691X(01)00664-1

[15] Farrell, P.B., Presicce, G.A., Brockett, C.C. and Foote, R.H. (1998) Quantification of Bull Sperm Characteristics Measured by Computer-Assisted Sperm Analysis (CASA) and the Relationship to Fertility. Theriogenology, 49, 871-879. http://dx.doi.org/10.1016/S0093-691X(98)00036-3

[16] Kathiravan, P., Kalatharan, J., Karthikeya, G., Rengarajan, K. and Kadirvel, G. (2011) Objective Sperm Motion Analysis to Assess Dairy Bull Fertility Using Computer-Aided System-A Review. Reproduction in Domestic Animals, 46, 165-172. http://dx.doi.org/10.1111/j.1439-0531.2010.01603.x

[17] Lin, C., Tholen, E., Jennen, D., Ponsuksili, S., Schellander, K. and Wimmers, K. (2006) Evidence for Effects of Testis and Epididymis Expressed Genes on Sperm Quality and Boar Fertility Traits. Reproduction in Domestic Animals, 41, 538-543. http://dx.doi.org/10.1111/j.1439-0531.2006.00710.x

\section{List of Abbreviations}

Base Pair (bp)

Computer-Assisted Semen Analysis (CASA)

Deoxynucleotide (dNTP)

Dulbecco’s Phosphate Buffered Saline (PBS)

Osteopontin (OPN)

Polymerase Chain Reaction (PCR)

Single Nucleotide Polymorphisms (SNP)

TRIS-Borate-EDTA Buffer (TBE)

TRIS-EDTA Buffer (TE) 